\title{
CIRH1A augments the proliferation of RKO colorectal cancer cells
}

\author{
FENG GUO, JIAN-JUN CHEN and WEI-JUN TANG \\ Department of Gastrointestinal Surgery, Ren Ji Hospital, Shanghai Jiao Tong University \\ School of Medicine, Shanghai 200127, P.R. China
}

Received August 27, 2016; Accepted January 18, 2017

DOI: 10.3892/or.2017.5497

\begin{abstract}
Accumulating evidence suggests that ribosomal proteins may have extraribosomal functions in various physiological and pathological processes, including cancer. We analyzed the expression of the CIRH1A ribosomal protein in colorectal carcinoma and para-carcinoma samples by bioinformatics analyses of data extracted from The Cancer Genome Atlas and in colorectal cancer cell lines in vitro by qPCR. CIRH1A was highly expressed in carcinoma samples and colorectal cancer cells. We also transduced the RKO colorectal cancer (CRC) cell line with lentivirus-mediated small interfering RNAs (siRNAs) and studied the impact that this knockdown of CIRH1A expression had on cell growth. RNA interference (RNAi)-mediated inhibition of CIRH1A expression significantly suppressed proliferation and increased apoptosis of transduced cells, and tended to arrest them in $G_{1}$ phase. Our data suggest that CIRH1A plays a critical role in the proliferation, cell cycle distribution, and apoptosis of human malignant colorectal cells, and might therefore be a potential target for therapeutic strategies.
\end{abstract}

\section{Introduction}

Colorectal carcinoma (CRC) is the second most frequent cause of cancer-related deaths (1-4). Although the survival of patients with CRC has improved along with marked advances in diagnostic and therapeutic modalities, prognosis for $\mathrm{CRC}$ remains poor (5). Accordingly, there is an urgent need to develop new strategies for treating CRC.

Ribosome biogenesis by eukaryotes is a complex, subtly-regulated, and energy-consuming process (6). RNA polymerases I-III (RNAPs) and over 200 assembly factors (including accessory proteins and small nucleolar RNAs (snoRNAs) are required to manufacture the ribosome in the

Correspondence to: Dr Wei-Jun Tang, Department of Gastrointestinal Surgery, Ren Ji Hospital, Shanghai Jiao Tong University School of Medicine, 1630 Dongfang Road, Shanghai 200127, P.R. China

E-mail: drtangweijun@aliyun.com

Key words: apoptosis, CIRH1A, proliferation, RKO, TCGA nucleolus $(7,8)$. Underlying the intricateness of ribosome biogenesis are many pre-rRNA processing events that make the terminal mature rRNAs, the large catalytic subunits (LSU), and the small recognition subunits (SSU) of the ribosome (9). In eukaryotic cells, a large ribonucleoprotein (RNP), called the SSU processome, is involved in forming the SSU of the ribosome (10). The SSU processome is assembled co-transcriptionally with the $47 \mathrm{~S}$ precursor pre-rRNA in the nucleolus (11), and is a complex of the U3 snoRNA and over 70 associated proteins, including the U3 proteins (UTPs). The SSU processome is required for the assembly of the ribosomal SSU and for the maturation of the 18S rRNA SSU component (12). Studies have demonstrated that some defects in the assembly of ribosomes, notably arising from mutations in various factors involved in ribosome biogenesis and components of the SSU processome, results in human diseases, the so-called ribosomopathies (7).

A mutation in the SSU processome component, hUTP4/ Cirhin, results in North American Indian childhood cirrhosis (NAIC/CIRH1A; OMIM: 604901); a severe autosomal recessive intrahepatic cholestasis. Cirhin (NP_116219) is encoded by the CIRHIA gene (13). All NAIC patients have a homozygous mutation in CIRH1A that changes the conserved Arg565 to Trp (R565W) in Crihin (14). Presently, the only effective treatment for the disease is liver transplantation (15). A study showed that knockdown of CIRH1A caused biliary defects in zebrafish (16). However, no functional information is available so far for CIRH1A in human CRC.

In the present study, we analyzed the level of CIRH1A expression in pairs of colon and para-rectum adenocarcinomas in silico and in CRC cell lines in vitro. Subsequently, we transduced the RKO CRC cell line with a lentivirus-delivered small interfering RNA (siRNA) to study the impact CIRH1A knockdown has on the growth of human CRC cells in vitro.

\section{Materials and methods}

In silico expression analyses. RNAseq and RNAseqV2 data derived from 23 paired samples of colon and rectum adenocarcinomas were obtained from The Cancer Genome Atlas (TCGA) database (17). Data were normalized using trimmed mean of M-values (18) and quality controlled according to the observed biological coefficient of variation (19). Negative binomial dispersion was performed for assessing differences 
in gene expression (20-22). A P-value of $<0.05$ and fold changes $>2.0$ between carcinoma and para-carcinomas were considered statistically significant.

Cell lines. HCT116, RKO, LoVo, and HT-29 human colorectal cell lines were obtained from the Shanghai Cell Bank (Shanghai, China). Cell lines were maintained in RPMI-1640 medium $\left(\right.$ Gibco $^{\circledR}$, Shanghai, China) supplemented with 10\% fetal bovine serum (FBS; Zhejiang Tianhang Biotech Co. Ltd., Huzhou, China), $100 \mathrm{U} / \mathrm{ml}$ penicillin and $0.1 \mathrm{mg} / \mathrm{ml}$ streptomycin (Sangon Biotech Co. Ltd., Shanghai, China) at $37^{\circ} \mathrm{C}$ in a $5 \% \mathrm{CO}_{2}$ incubator.

$R T-q P C R$. Total RNA was extracted using the TRIzol ${ }^{\circledR}$ reagent (Invitrogen, Shanghai, China) and reverse transcribed into cDNA with a PrimeScript ${ }^{\circledR}$ 1st Strand cDNA Synthesis kit (Takara, Dalian, China) completed according to the manufacturer's instructions. Next, $1 \mu \mathrm{l}$ of cDNA was used as a template for real-time quantitative PCR (qPCR). The sequences for CIRH1A primers were 5'-TGA GTC TCG GGC TAC AGA AG-3' (forward) and 5'-GCA TAC TTG ATG TTT AAC GCC TG-3' (reverse). The sequences for GAPDH internal control primers were 5'-TGA CTT CAA CAG CGA CAC CCA-3' (forward) and 5'-CAC CCT GTT GCT GTA GCC AAA-3' (reverse). Each qPCR occurred over an initial denaturation at $95^{\circ} \mathrm{C}$ for $20 \mathrm{sec}$, followed with 45 cycles of denaturation at $95^{\circ} \mathrm{C}$ for $5 \mathrm{sec}$ and extension $60^{\circ} \mathrm{C}$ for $30 \mathrm{sec}$. The PCR products of CIRH1A and GAPDH were 114 and $121 \mathrm{bp}$, respectively. All samples were examined in triplicates. Relative quantitation of gene expression was calculated as described previously (23).

Construction of recombinant lentiviral vector and cell transduction. A siRNA that targets the human UTP4/CIRHIA gene (Genbank no. NM_032830) with view of specifically knocking down RIHR1A expression was designed from the full-length UTP4/CIRHIA sequence by GeneChem Co. Ltd. (Shanghai, China). The siRNA sequence was TTG TGA AGA GCC ATC TCA T. For testing knockdown efficiencies, the stem-loop oligonucleotides were synthesized and inserted into a lentivirus-based pGV115-GFP (GeneChem Co. Ltd.) with $A g e \mathrm{I} / E c o$ RI sites. Lentivirus particles were prepared as described previously (24).

For cell transduction, RKO cells $\left(2 \times 10^{5}\right.$ cells/well) were cultured in 6-well plates and infected with either a CIRH1AsiRNA (shCIRH1A) lentivirus or negative control (shCtrl) lentivirus at a multiplicity of infection (MOI) of 20. Cells were incubated in a $5 \% \mathrm{CO}_{2}$ incubator at $37^{\circ} \mathrm{C}$ for 5 days. After $72 \mathrm{~h}$ of transduction, cells were observed under a fluorescence microscope (MicroPublisher 3.3RTV; Olympus, Tokyo, Japan). After 5 days of transduction, the knockdown efficiency was determined with qPCR and western blotting.

Western blotting. The expression of CIRH1A was determined at the protein level by immunostaining with a specific anti-CIRH1A antibody. After $48 \mathrm{~h}$ of lentiviral infection, cells were lysed using lysis buffer $(50 \mathrm{mM}$ Tris, $\mathrm{pH} 7.4$, $150 \mathrm{mMNaCl}, 1 \%$ SDS, $1 \mathrm{mM}$ EDTA, $1 \%$ NP-40) containing $1 \mathrm{mM}$ PMSF (Sangon Biotech Co. Ltd.) for $30 \mathrm{~min}$ on ice. The lysates were centrifuged at $10,000 \mathrm{x}$ g for $10 \mathrm{~min}$ at $4^{\circ} \mathrm{C}$, and the supernatants were collected. Protein concentration was determined using a BCA Protein assay kit (Sangon Biotech Co. Ltd.). Next, $10 \mathrm{mg}$ protein sample of each treatment was separated using $12.5 \%$ SDS-PAGE as per the Laemmli method (25), and transferred to polyvinylidene difluoride (PVDF) membrane (Sangon Biotech Co. Ltd.).

Membranes were incubated with mouse anti-FLAG (Sigma-Aldrich ${ }^{\circledast}$, Shanghai, China) or anti-GAPDH antibodies (1:1,000 dilution, Santa Cruz Biotechnology, Santa Cruz, CA, USA) at $4^{\circ} \mathrm{C}$ overnight. Membranes were then subsequently developed with a horseradish peroxidase (HRP)conjugated goat anti-mouse IgG (1:1,500 dilution, Santa Cruz Biotechnology) at $37^{\circ} \mathrm{C}$ for $1 \mathrm{~h}$ and was detected with EasyBlot ECL kit (Sangon Biotech).

Cell growth assay. Cell growth was measured by multiparametric high-content screening (HCS) performed with slight modifications to the protocol described previously (26). Briefly, infected RKO cells within the logarithmic growth phase were seeded in 96-well plates $(2,000$ cells/well $)$ and incubated for 5 days at $37^{\circ} \mathrm{C}$ in a $5 \% \mathrm{CO}_{2}$ incubator. At least 800 cells/well in the plates were counted using the Cellomics ArrayScan $^{\mathrm{TM}}$ VT1 HCS automated reader (Cellomics Inc. Pittsburgh, PA, USA) for measuring cell growth each day for all 5 days of growth. Each experiment was performed in triplicate.

Methyl-thiazol-tetrazolium (MTT) assay. Infected RKO cells $\left(2 \times 10^{3}\right.$ cells) were reseeded into 96 -well plate suspended in $100 \mu 1$ medium per well, and cultured at $37^{\circ} \mathrm{C}$. The proliferation of cells was detected at days 1, 2, 3, 4 and 5. Briefly, $20 \mu 1$ MTT (5 mg/ml, Sigma-Aldrich, USA) per well was added and incubated for $4 \mathrm{~h}$ at $37^{\circ} \mathrm{C}$. After removing the cell media, $150 \mu \mathrm{l}$ dimethyl sulfoxide (DMSO, Sigma-Aldrich) was added to each well for dissolution of the crystals. The absorbance was measured at $570 \mathrm{~nm}$.

Cell cycle distribution and apoptosis. Cell cycle distribution or apoptosis was analyzed using flow cytometry as described previously (27). Briefly, RKO cells were infected with shCIRH1A or shCtrl plasmids and incubated at $37^{\circ} \mathrm{C}$ for $1,2,3,4$ or 5 days. At each time point, cells were collected, washed twice with ice-cold PBS, fixed with $0.5 \mathrm{ml}$ ice-cold $70 \%$ ethanol for $1 \mathrm{~h}$ at $4^{\circ} \mathrm{C}$, and stained with propidium iodide $(50 \mu \mathrm{g} / \mathrm{ml}$; Sigma-Aldrich in the presence of RNase A $(100 \mu \mathrm{g} / \mathrm{ml}$; Sangon Biotech). The cell cycle distribution was alluded from the DNA content analyzed with a BD FACSCalibur Flow Cytometer (BD Biosciences, San Diego, CA, USA). Each experiment was performed in triplicate.

Cell apoptosis with the Annexin V-APC stain detection by flow cytometry. Briefly, RKO cells (1,000 cells/well) were cultured in 6-well plates. After $48 \mathrm{~h}$ of infection with either an shCIRH1A or shCtrl plasmid, cells were collected and washed twice with ice-cold PBS. The cell concentrations were adjusted to $1 \times 10^{6} \%$ $\mathrm{ml}$ with 1X staining buffer (Sangon Biotech), of which $100 \mu \mathrm{l}$ of cell suspension was stained with $5 \mu$ Annexin V-APC (BD Biosciences) for $15 \mathrm{~min}$ at room temperature in the dark. Cells were analyzed using flow cytometry within $1 \mathrm{~h}$ of staining. Each experiment was performed in triplicate. 

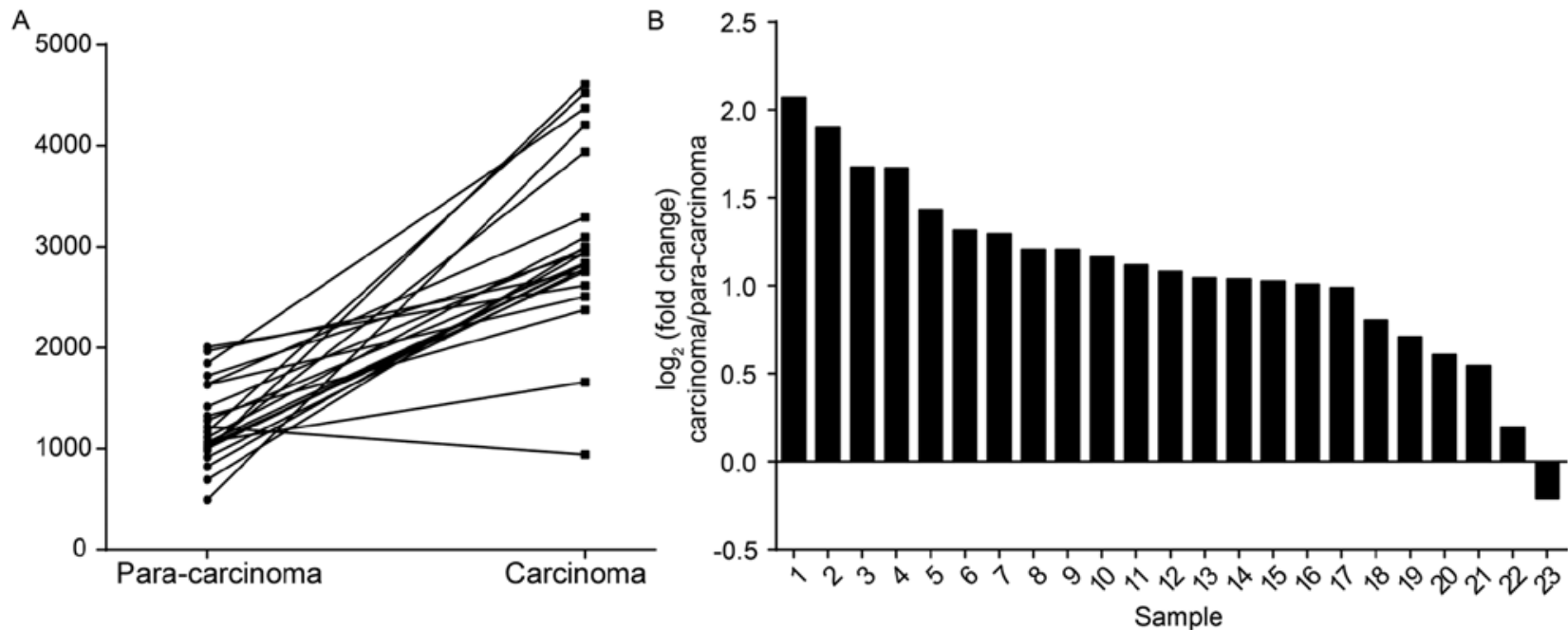

Figure 1. CIRH1A mRNA is overexpressed in colorectal carcinoma over paired para-carcinoma tissues. (A) Original data of CIRH1A expression in gene expression data of colorectal and para-carcinoma tissues from the TCGA. (B) $\log _{2}$-fold changes of CIRH1A expression in colorectal cancer compared with that in para-carcinoma tissues.

Colony formation assay. CIRH1A-siRNA and control cells were resuspended in RPMI-1640 medium at logarithmic growth phase. Cells were seeded onto 6-well plates at a density of 800 cells/well. The cells were incubated over a period of 14 days. Cell colonies were photographed by fluorescence microscopy (MicroPublisher 3.3RTV; Olympus, Tokyo, Japan). The cells were fixed with paraformaldehyde $(1 \mathrm{ml} /$ well; Sangon Biotech) for $30 \mathrm{~min}$. The cells were washed with PBS and then stained with $500 \mu$ l Giemsa (Sangon Biotech) for $20 \mathrm{~min}$. Then, the cells were washed with $\mathrm{ddH}_{2} \mathrm{O}$ several times and left to dry at room temperature. A digital camera was used for imaging and to obtain colony counts.

Statistical analyses. Statistical analyses were performed with SPSS version 16.0 for Windows (SPSS, Chicago, IL, USA). Data are expressed as the mean \pm SD. Raw data were submitted to Student's t-test to analyze for differences between two groups. A P-value of $<0.05$ was considered statistically significant.

\section{Results}

CIRHIA gene expression is markedly higher in colorectal cancer over para-carcinoma tissue. To examine a possible link of CIRH1A and colorectal cancer, we analyzed the gene expression data of 23 colorectal cancer cases with paired para-carcinoma tissues from The Cancer Genome Atlas (TCGA). The data revealed a highly significant correlation between CIRH1A mRNA expression and colorectal cancer (Fig. 1A; $\mathrm{P}<0.01$ ). The average expression of CIRH1A was more than 2-fold greater in CRC tissues over para-carcinomas (Fig. 1B).

CIRHIA mRNA detection in four colorectal cancer cells. We determined the expression of CIRH1A mRNA in the HT119, RKO, LoVo, and HT-29 CRC cell lines by RT-PCR. The data showed that CIRHIA mRNA was highly expressed in HT119, RKO, and LoVo cell lines (Fig. 2).

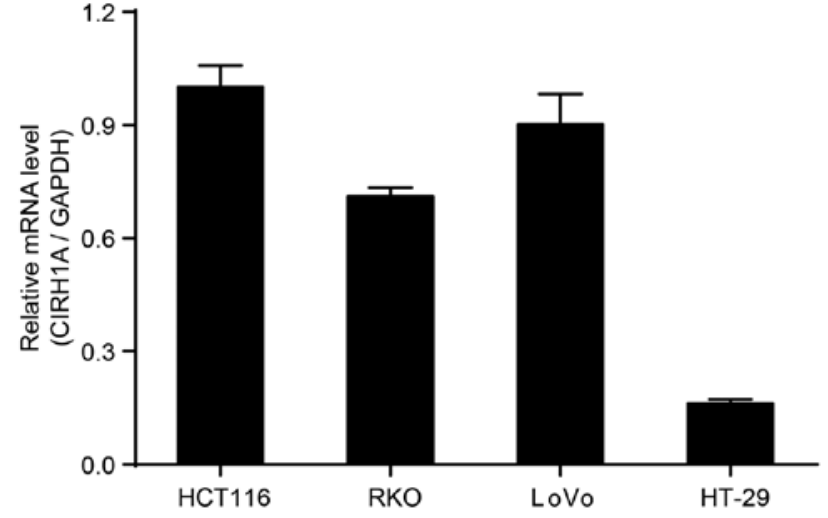

Figure 2. CIRH1A mRNA levels in four colorectal cell lines. CIRH1A expression levels determined by RT-PCR.

Lentivirus-mediated knockdown of CIRHIA in RKO cells. To explore the role of CIRH1A, we knocked down the expression of CIRH1A in the RKO cell line. At 3 days post-infection, $>80 \%$ of the cells were successfully infected with either a shCIRH1A lentivirus or shCtrl lentivirus (Fig. 3A). As determined by qPCR at 5 days post-infection, shCIRH1A-infected cultures had significantly lower levels of CIRH1A mRNA compared to levels in control cultures infected with a shCtrl lentivirus (Fig. 3B). Western blotting for the CIRH1A protein confirmed that CIRH1A levels were greatly reduced in cells infected with a shCIRH1A payload, thereby indicating an effective knockdown of the target gene (Fig. 3C).

Knocking down CIRHIA in RKO cells inhibits cell proliferation. To examine the influence CIRH1A has on cell growth, RKO cells expressing either a shCIRH1A lentivirus or shCtrl lentivirus were seeded in 96-well plates and analyzed by Cellomics every day for 5 days. shCtrl-transduced cells expanded markedly over the 5 days of the experiment, while the number of shCIRH1A-transduced cells increased only slightly by comparison (Fig. 4). The data from this experiment 
A

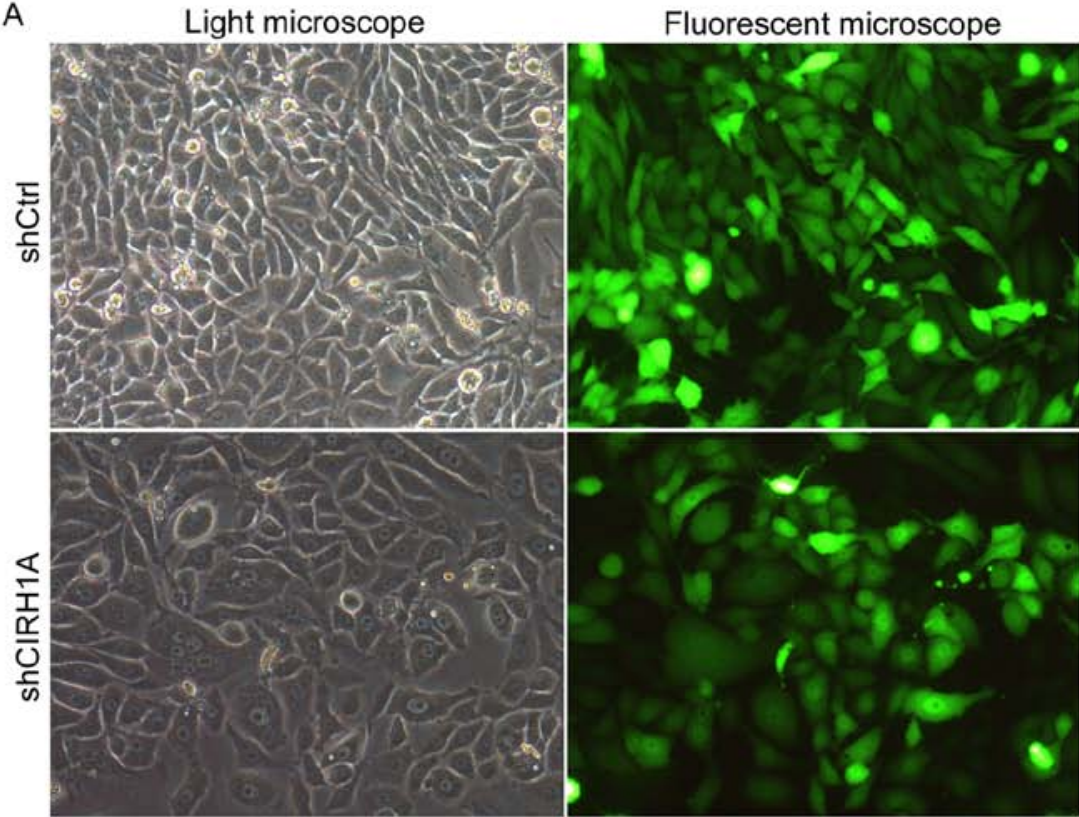

B

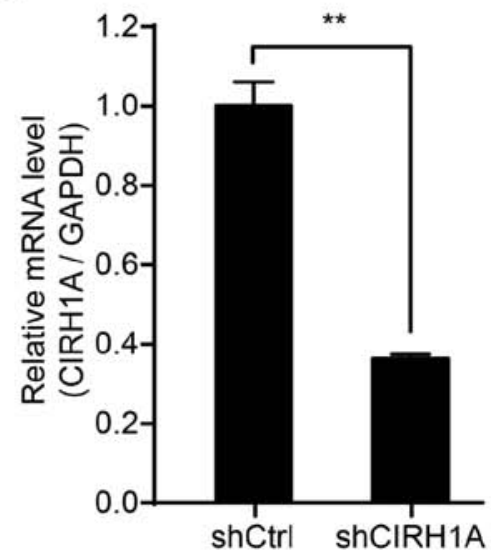

C ${ }_{\text {CIRH1A }}$

GAPDH

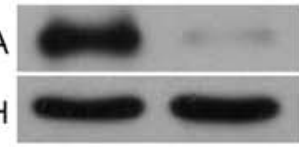

shCtrl shCIRH1A

Figure 3. Knockdown of CIRH1A in RKO cells infected with shCIRH1A or shCtrl-lentivirus vectors. (A) Cells were examined by fluorescent and light microscopy at day 3 post-infection (x200, magnification). Representative images of the cultures are shown. (B) CIRH1A mRNA levels were analyzed using qPCR at day 5 post-infection. CIRH1A mRNA level decreased significantly after CIRH1A knockdown. ${ }^{* *} \mathrm{P}<0.01$. (C) CIRH1A protein expression was analyzed by western blotting in shCtrl-transduced and shCIRH1A-transduced RKO cells.

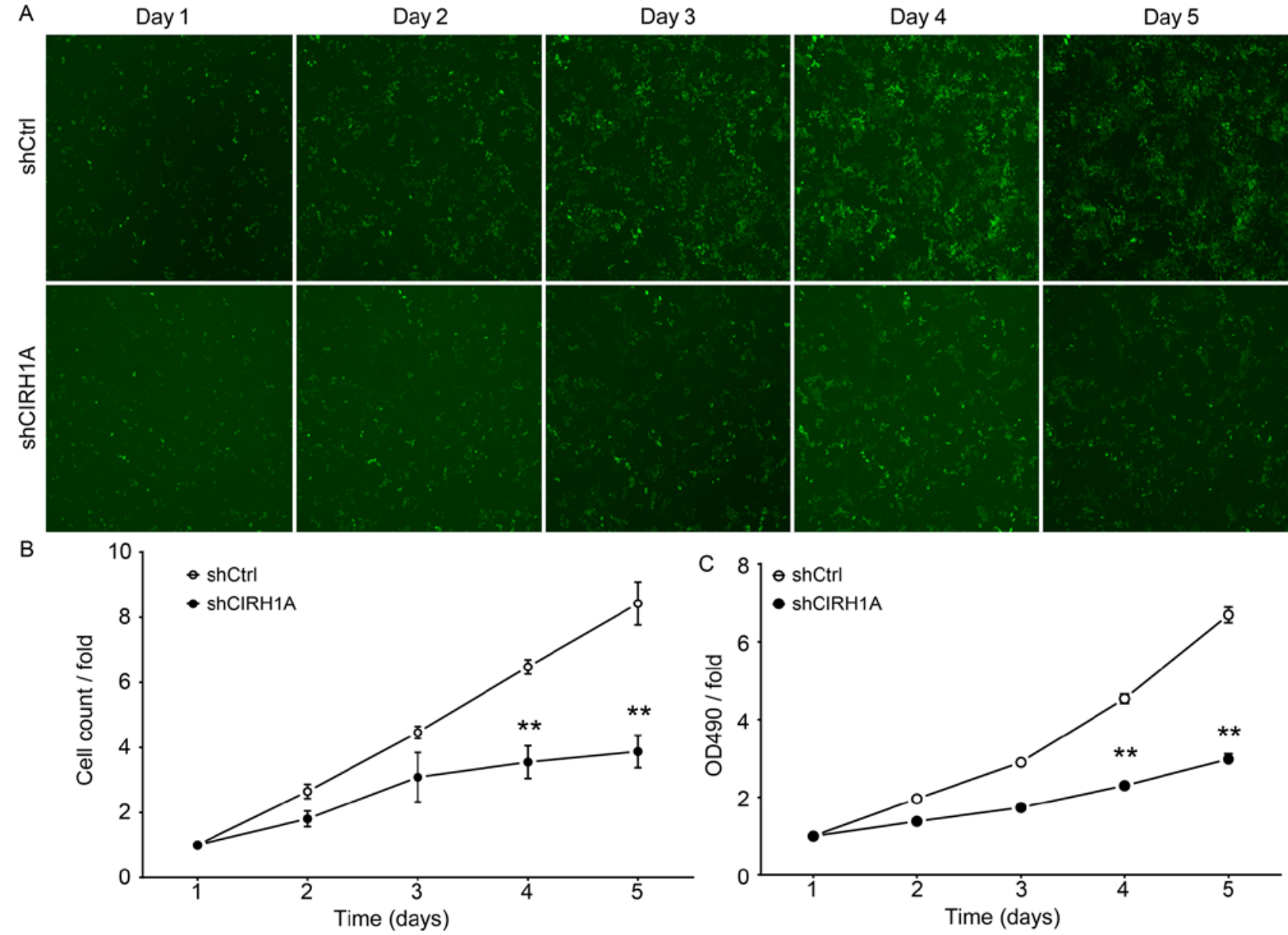

Day 3

Day 4

Day 5

Figure 4. Effect of CIRHIA knockdown on RKO cell growth. (A) Cells were infected with shCtrl or shCIRH1A lentivirus and visualized with high content cell imaging at days 1-5. (B) Growth of transduced cells was assayed every day for 5 days (shCtrl vs shCIRH1A, $\mathrm{P}<0.01$ ). (C) The in vitro proliferative abilities of RKO cells infected with shCtrl or shCIRH1A lentivirus were evaluated by MTT assay. Each value represents the mean $\pm \mathrm{SD}$ of the absorbance value $\left(\mathrm{OD}_{490}\right)$ (shCtrl vs shCIRH1A, $\mathrm{P}<0.01$ ). 

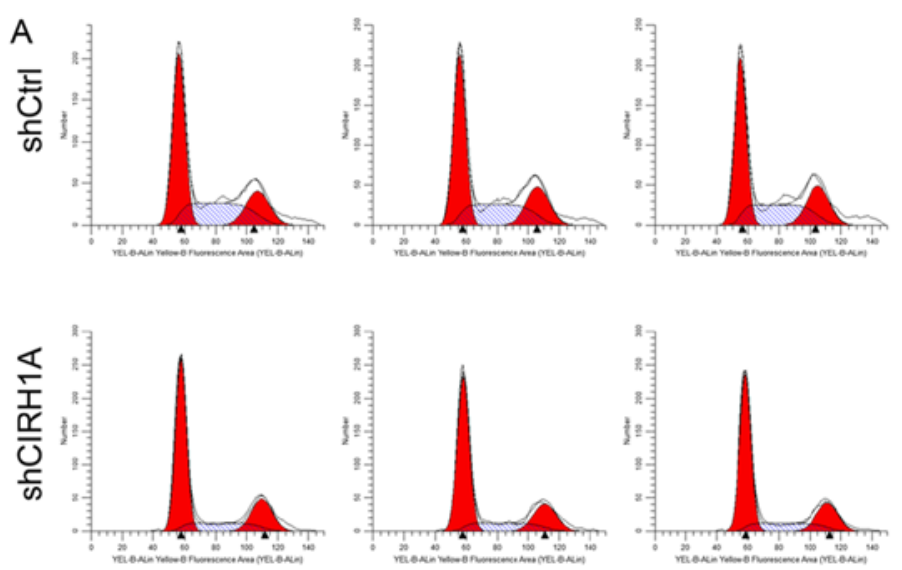

Figure 5. CIRH1A knockdown leads to cell cycle arrest. (A) Cell cycle distribution of RKO cells was analyzed by flow cytometry. Each group is shown in triplicates. Note $\mathrm{G}_{1}$ - and $\mathrm{G}_{2}$-phase arrests in the knockdown cells. (B) Cell cycle distributions determined by flow cytometry. Compared with shCtrl, shCIRH1A cultures showed a significant decrease in the proportion of cells in the $\mathrm{S}$ phase $(\mathrm{P}<0.01)$; however, there was a significant increase in proportion of cells in $\mathrm{G}_{1}$ and $\mathrm{G}_{2}$ phase compared with shCtrl group $\left({ }^{*} \mathrm{P}<0.05 ;{ }^{* *} \mathrm{P}<0.01\right)$.
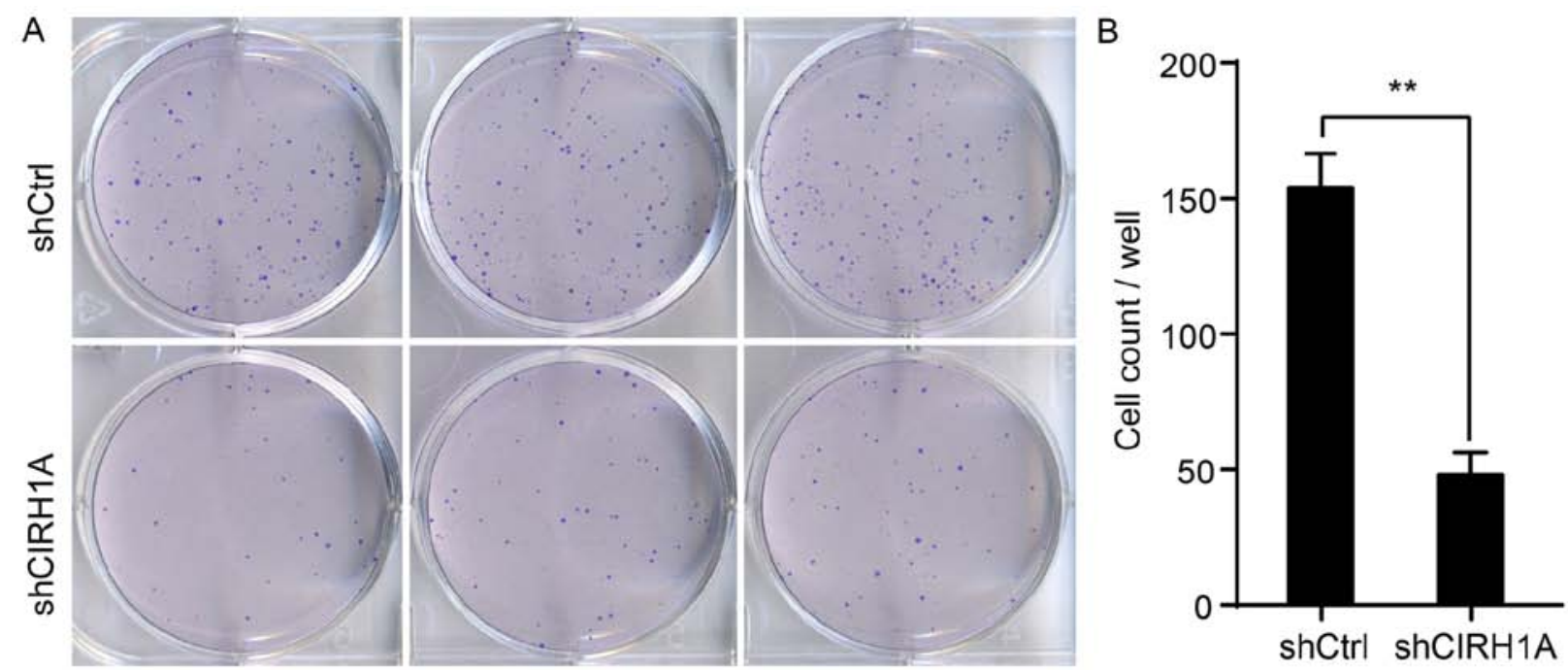

Figure 6. CIRH1A silencing represses RKO cell colony formation. (A) Photomicrographs of Giemsa-stained colonies of RKO cells growing in 6-well plates for 10 days after infection. (B) The number of cells in each colony of RKO cells was counted. Cell number in shCIRH1A group was significantly fewer relative to shCtrl-transduced cells $\left({ }^{* *} \mathrm{P}<0.01\right)$.

suggest that CIRHIA knockdown significantly inhibited the proliferation of RKO cells.

The effect of CIRH1A protein reduction on RKO cell proliferation was also determined with MTT assay. Although shCtrl and shCIRH1A cells had similar growth on days 1-3, cells transduced with shCIRH1A had significantly suppressed growth on days 4 and 5 by comparison (Fig. 4C). Seemingly the growth of RKO cells in vitro is dependent on CIRH1A expression.

Knockdown of CIRH1A leads to cell cycle arrest. To determine the necessity of CIRH1A for cell cycle progression, we determined the cell cycle distribution of RKO cells with intact or knockdown expression of CIRH1A (Fig. 5A). The shCtrl group displayed the following distribution: $\mathrm{G}_{1}$ phase, $48.98 \pm 0.55 \%$; $S$ phase, $30.84 \pm 0.96 \% ; \mathrm{G}_{2}$ phase, $20.17 \pm 1.49 \%$; whilst the shCIRH1A group displayed the following: $\mathrm{G}_{1}$ phase,
$61.65 \pm 0.25 \%$; $S$ phase, $17.38 \pm 0.45 \% ; \mathrm{G}_{2}$ phase, $20.97 \pm 0.57 \%$. shCIRH1A-lentivirus cultures had a significant decrease in the percentage of cells in the $S$ phase $(P<0.01)$ and an increase in the percentage of cells in $G_{1}$ phase $(P<0.01)$ relative to control cultures (Fig. 5B). Taken together, the data suggest that CIRH1A regulates cell growth and blocks cell cycle progression in the $G_{1}$ phase.

CIRHIA knockdown inhibits colony formation in RKO cells. Finally, we labelled RKO cells with the Giemsa stain to measure the effects of CIRHIA knockdown on formation of RKO cell colonies (Fig. 6A). As presented in Fig. 6B, the cell number in a single colony was significantly fewer in the shCIRH1A group compared to the shCtrl group (shCtrl: $154 \pm 12$ vs. shCIRH1A: $48 \pm 8 ; \mathrm{P}<0.01$ ). This result indicates that reducing $C I R H 1 A$ expression endogenously can significantly inhibit the growth of colorectal carcinomas. 


\section{Discussion}

North American Indian childhood cirrhosis (NAIC/CIRH1A) (OMIM: 604901) is an infrequent, autosomal recessive familial cholestasis found exclusively in Canadian Ojibway-Cree children. NAIC patients suffer from neonatal jaundice, progressing to biliary cirrhosis and portal hypertension (7). Liver transplantation is the only known treatment (15). CIRHIA, the human homolog of yeast Utp4, was located to chromosome 16q22 (28). Analyses for single nucleotide polymorphisms have revealed that NAIC patients present with a R565W mutation in human Cirhin encoded with CIRHIA (14).

Studies show that Cirhin might play various roles in different organisms. As a member of the t-Utp/UtpA subcomplex of the SSU processome, for example, the yeast 'equivalent' of human Cirhin, Utp4 was required for pre-rRNA processing and transcription, and for the assembly of the SSU processome $(10,11)$. Moreover, an Utp4 mutation did not affect ribosome biogenesis in yeast (6). However, the orthologue in human, Cirhin is only required for pre-18S rRNA processing, but not for pre-rRNA transcription (29). Cirhin in mouse (mCirhin) is expressed not only in fetal liver, but also in other developing tissues (14). Knockout (-/-) of mCirhin (also known as TEX292) is lethal to embryos (30), while heterozygotes (+/-) are phenotypically normal (31). Yeast two-hybrid $(\mathrm{Y} 2 \mathrm{H})$ analysis of a human liver cDNA library revealed Cirhin interacts with the nucleolar protein NOL11 (32). Further functional analysis revealed that NOL11 is required for pre-rRNA processing and transcription, as well as for maintaining a normal nucleolar morphology. In another study, human Cirhin interacted with Cirip, which is required for transcription of the HIV-1 LTR enhancer element (31). However, CIRHIA expression and its function in human cancers, and CRC in particular, have not been studied hitherto.

In the present study, we first determined the expression levels of CIRH1A mRNA in silico using clinical and molecular data extracted from the online TCGA and in vitro by profiling four CRC cell lines. The data showed first that CIRH1A mRNA was highly expressed in carcinoma compared with paired para-carcinomas, and second that it was overexpressed in the HCT116, RKO, and LoVo cell lines. Thereafter, in order to assess the contribution of CIRHIA to CRC cell lines, we constructed a shCIRH1A lentiviral vector, which efficiently silenced CIRHIA in infected RKO cells. Compared to shCtrl-infected cells, shCIRH1A-treated cells showed decreased proliferation and a significant increase in the proportion of cells in $\mathrm{G}_{1}$ phase. Furthermore, we found that knockdown of CIRHIA increased apoptosis in RKO cells. Taken together, the data suggest that CIRHIA plays a novel role in promoting the growth of CRCs in addition to its known function in ribosomal biogenesis. A further study to validate the anti-apoptotic role of CIRHIA in tumorigenesis of CRC is ongoing.

In conclusion, we have demonstrated here that the downregulation of CIRHIA expression within RKO CRC cells by RNAi inhibited their proliferation and induced apoptosis. Accordingly, knockdown of CIRHIA by lentivirus-siRNA may be a putative therapeutic approach for treating colorectal cancers that overexpress CIRHIA.

\section{References}

1. Khan K, Cunningham D and Chau I: Targeting angiogenic pathways in colorectal cancer: Complexities, challenges and future directions. Curr Drug Targets 18: 56-71, 2017.

2. Cunningham D, Atkin W, Lenz HJ, Lynch HT, Minsky B, Nordlinger B and Starling N: Colorectal cancer. Lancet 375: 1030-1047, 2010

3. Chen W, Zheng R, Baade PD, Zhang S, Zeng H, Bray F, Jemal A, Yu XQ and He J: Cancer statistics in China, 2015. CA Cancer J Clin 66: 115-132, 2016.

4. Siegel RL, Miller KD and Jemal A: Cancer statistics, 2016. CA Cancer J Clin 66: 7-30, 2016.

5. Qian WF, Guan WX, Gao Y, Tan JF, Qiao ZM, Huang H and Xia CL: Inhibition of STAT3 by RNA interference suppresses angiogenesis in colorectal carcinoma. Braz J Med Biol Res 44: 1222-1230, 2011

6. Freed EF and Baserga SJ: The C-terminus of Utp4, mutated in childhood cirrhosis, is essential for ribosome biogenesis. Nucleic Acids Res 38: 4798-4806, 2010.

7. Sondalle SB and Baserga SJ: Human diseases of the SSU processome. Biochim Biophys Acta 1842: 758-764, 2014.

8. Doudna JA and Rath VL: Structure and function of the eukaryotic ribosome: The next frontier. Cell 109: 153-156, 2002.

9. Henras AK, Soudet J, Gérus M, Lebaron S, Caizergues-Ferrer M, Mougin A and Henry Y: The post-transcriptional steps of eukaryotic ribosome biogenesis. Cell Mol Life Sci 65: 2334-2359, 2008.

10. Dragon F, Gallagher JE, Compagnone-Post PA, Mitchell BM, Porwancher KA, Wehner KA, Wormsley S, Settlage RE, Shabanowitz J, Osheim Y, et al: A large nucleolar U3 ribonucleoprotein required for $18 \mathrm{~S}$ ribosomal RNA biogenesis. Nature 417: 967-970, 2002.

11. Gallagher JE, Dunbar DA, Granneman S, Mitchell BM, Osheim Y, Beyer AL and Baserga SJ: RNA polymerase I transcription and pre-rRNA processing are linked by specific SSU processome components. Genes Dev 18: 2506-2517, 2004.

12. Phipps KR, Charette J and Baserga SJ: The small subunit processome in ribosome biogenesis - progress and prospects. Wiley Interdiscip Rev RNA 2: 1-21, 2011.

13. Yu B, Mitchell GA and Richter A: Nucleolar localization of cirhin, the protein mutated in North American Indian childhood cirrhosis. Exp Cell Res 311: 218-228, 2005.

14. Chagnon P, Michaud J, Mitchell G, Mercier J, Marion JF, Drouin E, Rasquin-Weber A, Hudson TJ and Richter A: A missense mutation (R565W) in cirhin (FLJ14728) in North American Indian childhood cirrhosis. Am J Hum Genet 71: 1443-1449, 2002.

15. Drouin E, Russo P, Tuchweber B, Mitchell G and RasquinWeber A: North American Indian cirrhosis in children: A review of 30 cases. J Pediatr Gastroenterol Nutr 31: 395-404, 2000.

16. Wilkins BJ, Lorent K, Matthews RP and Pack M: p53-mediated biliary defects caused by knockdown of cirh1a, the zebrafish homolog of the gene responsible for North American Indian Childhood Cirrhosis. PLoS One 8: e77670, 2013.

17. Muzny DM, Bainbridge MN, Chang K, Dinh HH, Drummond JA, Fowler G, Kovar CL, Lewis LR, Morgan MB, Newsham IF, et al; Cancer Genome Atlas Network: Comprehensive molecular characterization of human colon and rectal cancer. Nature 487: 330-337, 2012.

18. Robinson MD and Oshlack A: A scaling normalization method for differential expression analysis of RNA-seq data. Genome Biol 11: R25, 2010.

19. Robinson MD, McCarthy DJ and Smyth GK: edgeR: A Bioconductor package for differential expression analysis of digital gene expression data. Bioinformatics 26: 139-140, 2010.

20. Yu D, Huber W and Vitek O: Shrinkage estimation of dispersion in Negative Binomial models for RNA-seq experiments with small sample size. Bioinformatics 29: 1275-1282, 2013.

21. Robinson MD and Smyth GK: Small-sample estimation of negative binomial dispersion, with applications to SAGE data. Biostatistics 9: 321-332, 2008.

22. Lund SP, Nettleton D, McCarthy DJ and Smyth GK: Detecting differential expression in RNA-sequence data using quasi-likelihood with shrunken dispersion estimates. Stat Appl Genet Mol Biol 11: 307-314, 2012.

23. Livak KJ and Schmittgen TD: Analysis of relative gene expression data using real-time quantitative PCR and the 2(-Delta Delta C(T)) method. Methods 25: 402-408, 2001. 
24. Lois C, Hong EJ, Pease S, Brown EJ and Baltimore D: Germline transmission and tissue-specific expression of transgenes delivered by lentiviral vectors. Science 295: 868-872, 2002.

25. Laemmli UK: Cleavage of structural proteins during the assembly of the head of bacteriophage T4. Nature 227: 680-685, 1970.

26. Zhou Y, Su Z, Huang Y, Sun T, Chen S, Wu T, Chen G, Xie X, $\mathrm{Li} \mathrm{B}$ and Du Z: The Zfx gene is expressed in human gliomas and is important in the proliferation and apoptosis of the human malignant glioma cell line U251. J Exp Clin Cancer Res 30: 114, 2011.

27. Milner AE, Levens JM and Gregory CD: Flow cytometric methods of analyzing apoptotic cells. Methods Mol Biol 80: 347-354, 1998.

28. Bétard C, Rasquin-Weber A, Brewer C, Drouin E, Clark S, Verner A, Darmond-Zwaig C, Fortin J, Mercier J, Chagnon P, et al: Localization of a recessive gene for North American Indian childhood cirrhosis to chromosome region 16q22-and identification of a shared haplotype. Am J Hum Genet 67: 222-228, 2000.
29. Prieto JL and McStay B: Recruitment of factors linking transcription and processing of pre-rRNA to NOR chromatin is UBF-dependent and occurs independent of transcription in human cells. Genes Dev 21: 2041-2054, 2007.

30. Richter A, Mitchell GA and Rasquin A: North American Indian childhood cirrhosis (NAIC). Med Sci (Paris) 23: 1002-1007, 2007 (In French).

31. Yu B, Mitchell GA and Richter A: Cirhin up-regulates a canonical NF-kappaB element through strong interaction with Cirip/HIVEP1. Exp Cell Res 315: 3086-3098, 2009.

32. Freed EF, Prieto JL, McCann KL, McStay B and Baserga SJ: NOL11, implicated in the pathogenesis of North American Indian childhood cirrhosis, is required for pre-rRNA transcription and processing. PLoS Genet 8: e1002892, 2012. 